\title{
RENDEMEN SELULOSA HASIL EKSTRAKSI BATANG TANAMAN JAGUNG (Zea mays) MENGGUNAKAN VARIASI LAMA BLANCHING DAN KONSENTRASI NaOH
}

\author{
[Yield and Charateristics of Cellulose from Stalks of Corn Plant (Zea mays) Extraction Using Different \\ Blanching Time and Concentration of $\mathrm{NaOH}]$
}

\author{
Novian Wely Asmoro, Afriyanti, Ismawati \\ Program Studi Teknologi Hasil Pertanian, Fakultas Pertanian, Universitas Veteran Bangun Nusantara, Sukoharjo \\ *Email: novianwelyasmoro@gmail.com
}

Diterima 12 Januari 2018/ Disetujui 20 April 2018

\begin{abstract}
The aim of this study to determine the effect of $\mathrm{NaOH}$ concentration on cellulose extraction process from corn stalks to its yield and physical properties of cellulose. Method of study included: extraction of corn plant cellulose through processed of delignification, washed, blanched, dried and grinded of cellulose powder. The experiment used the extraction time for 60 minutes with the concentration of $\mathrm{NaOH}$ with 5 treatment level that was $10 \%, 15 \%, 20 \%, 25 \%$ and $30 \%$. Each treatment was repeated three times and each was analyzed with two replications. The experimental unit obtained $3 \times 5 \times 2=30$ units of experiment. Physical cellulose product analysis included measurement of yield, $\mathrm{pH}$, Water Holding Capacity (WHC) and Oil Holding Capacity $(\mathrm{OHC})$. The results showed that the use 10\% NaOH concentration obtained yield of 32.41\%; $\mathrm{pH}$ value of 8.33; water holding capacity (WHC) was $7.8 \mathrm{~g} / \mathrm{g}$; the oil holding capacity $(\mathrm{OHC})$ was $8.33 \mathrm{~g} / \mathrm{g}$ and water content was $7.96 \%$
\end{abstract}

Keywords: Blanching, cellulose, stalks of corn plants, extraction, Sodium Hydroxide

\begin{abstract}
ABSTRAK
Selulosa merupakan salah satu senyawa polimer yang dapat disintesis dari bahan-bahan tanaman, termasuk limbah kegiatan pertanian antara lain batang singkong, jerami, tandan kosong kelapa sawit, tongkol jagung dan batang tanaman jagung. Tujuan penelitian ini adalah untuk mengetahui pengaruh konsentrasi $\mathrm{NaOH}$ dan lama waktu delignifikasi pada proses ekstraksi selulosa dari batang tanaman jagung. Metode ekstraksi selulosa diawali dengan proses penyiapan bahan batang tanaman jagung, proses delignifikasi, pencucian, blanching, pengeringan dan pembuatan serbuk selulosa. Rancangan percobaan yang digunakan yaitu rancangan acak lengkap dengan dua faktor perlakuan dan dua ulangan. Lama waktu (T) dengan 3 taraf perlakuan, yaitu: T1= 60 menit, T2= 90 menit dan T3= 120 menit serta konsentrasi $\mathrm{NaOH}(\mathrm{K})$ dengan 5 taraf perlakuan yaitu $\mathrm{K} 1=10 \%, \mathrm{~K} 1=15 \%, \mathrm{~K} 2=20 \%, \mathrm{~K} 3=25 \%$ dan $\mathrm{K} 4=30 \%$. Masing-masing perlakuan diulang dua kali. Sehingga diperoleh unit percobaan $3 \times 5 \times 2=30$ unit percobaan. Analisis produk selulosa secara fisik dan kimia meliputi analisis pengukuran rendemen, kadar air, pH, analisis Water Holding Capacity (WHC) dan Oil Holding Capacity $(\mathrm{OHC})$. Penggunaan $\mathrm{NaOH}$ konsentrasi $10 \%$ dengan waktu blanching 60 menit dapat digunakan pada proses ekstraksi selulosa batang jagung yang menghasilkan rendemen tertinggi sebesar $32,41 \%$ nilai pH 8,33; WHC rata-rata 7,8 g/g; OHC rata-rata $8,33 \mathrm{~g} / \mathrm{g}$ dan kadar air rata-rata $7,96 \%$
\end{abstract}

Kata kunci: Batang tanaman jagung, Blanching, Ekstraksi, $\mathrm{NaOH}$, Selulosa

\section{PENDAHULUAN}

Limbah organik dari kegiatan pertanian memiliki kandungan selulosa, hemiselulosa, dan lignin, dapatdimanfaatkan sebagai sumber selulosa karena sebagian besar limbah hasil pertanian tersebut tersusun atas selulosa pada dinding selnya.Selulosa $\left(\mathrm{C}_{6} \mathrm{H}_{10} \mathrm{O}_{5}\right) \mathrm{n}$ merupakan molekul rantai panjangtersusun atas polimer polisakarida dari beta glukosa (Israel et al. 2008). Isolasi selulosa dapat dilakukan pada limbah atau sisa-sisa kegiatan pertanian antara lain limbah kelapa sawit, tongkol jagung, sagu, bambu, enceng gondok, limbah kulit kakao, bagase, batang tanaman dan limbah pertanian lainnya.Pada beberapa penelitian ekstraksi selulosa seperti pada cake kernel kelapa sawit memiliki kandungan selulosa sekitar 20-30\%, kandungan selulosa pada kulit gandum, kulit padi, fiber pada tomat, batang pisang, tandan kosong kelapa sawit dan tongkol jagung berturut-turut 32,2\%; 24,4\%; 19,7\%; 37,5\%; $34,15 \%$ dan 44,9\%.(Bono et al. 2009; Wijayani et al. 2005; Yan et al. 2009; Hutomo 2012; Melisa et al. 2014; Azubuike \& Okhamafe 2012; Veeramachineni et al. 2016) Aplikasi selulosa secara luas yang spesifik untuk produk pangan dapat dibedakan dari karakteristik fisik dan kimia 
hasil turunan (modifikasi) selulosa. Beberapa turunan selulosa yang secara komersil banyak dikembangkan antara lainmethylcellulose (MC), carboxymethyl cellulose (CMC), hydroxypropyl cellulose (HPC), danhydroxypropylmethyl cellulose (HPMC). Turunan selulosa merupakan hasil modifikasi fisik dan kimia yang digunakan dalam memperbaiki sifat reologi, emulsifikasi, stabilitas larutan, modifikasi pembentukan dan pertumbuhan kristal es, dan meningkatkan kapasitas pengikatan air (WHC) serta kapasitas pengikatan minyak (OHC). Selulosa dan produk turunannya dapat digunakan sebagai anti caking agent, emulsifier, stabilizer, agen dispersi, pengental, dan biodegradable films. Aplikasinya pada makanan atara lain: frozen dessert, kue/roti, saos, sirup, dan produk beverage, serta dapat juga dimanfaatkan sebagai edible coating film (Malmiri H. et al. 2011; Espinoza-Herrera et al. 2011; Jahit et al. 2016).

Proses ekstraksi selulosa dilakukan dengan jalan memisahkan komponen selulosa dari komponen lainnya pada bahan melalui proses ekstraksi asam dan ekstraksi basa maupun kombinasi keduanya yang melibatkan proses delignifikasi. Proses ekstraksi basa biasa menggunakan larutan $\mathrm{NaOH}$ dalam proses delignifikasi. Penelitian yang dilakukan oleh Widodo et al. (2013) sintesis a-selulosa dari limbah batang tanaman ubi kayumenggunakan $\mathrm{NaOH}$ sebagai pelarut alkali dengan konsentrasi $25 \%$ dan lama waktu 60 menit menghasilkan rendemen selulosa $67,69 \%$. Ekstraksi selulosa kulit buah kakao dengan menggunakan $\mathrm{NaOH} 12 \%$ dapat menghasilkan rendemen selulosa dengan sifat yang terbaik sebesar $26,09 \%$, penggunaan $\mathrm{NaOH}$ lebih dari $17 \%$ menyebabkan semakin menurunnya rendemen selulosa yang dihasilkan. Penggunaan alkali dalam proses delignifikasi dapat menghasilkan sifat dan jumlah rendemen selulosa yang berbeda-beda tergantung pada jenis bahan baku yang digunakan(Hutomo 2012; Bouredja et al. 2015)

Batang tanaman jagung merupakan salah satu biomasa limbah pertanian yang cukup banyak terdapat di Indonesia. Salah satu pemanfaatan batang tanaman jagung adalah sebagai pakan ternak, bahan bakar, dan kompos. Selain hal tersebut, limbah batang tanaman jagung dapat dimanfaatkan sebagai sumber selulosa sehingga meningkatkan nilai guna limbah hasil pertanian. Batang tanaman jagung mengandung selulosa $42,6 \%$, hemiselulosa $21,3 \%$, dan lignin 8,2\%.Limbah batang tanaman jagung yang tinggi akan kandungan selulosa \& hemiselulosa tersebut berpeluang sebagai salah satu alternatif sumber selulosa dalam berbagai kebutuhan industri(Sarkar et al. 2012). Ekstraksi selulosa batang tanaman jagung ditujukan untuk mendapatkan rendemen yang tinggi dan dapat memiliki karakteristik fisik dan kimia yang dapat diaplikasikan dalam proses pengolahan makanan dan industri.

Proses ekstraksi selulosa dilakukan dengan jalan memisahkan komponen selulosa dari komponen lainnya pada bahan melalui proses ekstraksi asam dan ekstraksi basa maupun kombinasi keduanya yangmelibatkan proses delignifikasi. Proses ekstraksi basa biasa menggunakan larutan $\mathrm{NaOH}$ dalam proses delignifikasi. Penelitian yang dilakukan oleh Widodo et al. (2013) sintesis a-selulosa dari limbah batang tanaman ubi kayumenggunakan $\mathrm{NaOH}$ sebagai pelarut alkali dengan konsentrasi $25 \%$ dan lama waktu 60 menit menghasilkan rendemen selulosa 67,69\%. Ekstraksi selulosa kulit buah kakao dengan menggunakan $\mathrm{NaOH} 12 \%$ dapat menghasilkan rendemen selulosa dengan sifat yang terbaik sebesar $26,09 \%$, penggunaan $\mathrm{NaOH}$ lebih dari $17 \%$ menyebabkan semakin menurunnya rendemen selulosa yang dihasilkan. Penggunaan alkali dalam proses delignifikasi dapat menghasilkan sifat dan jumlah rendemen selulosa yang berbeda-beda tergantung pada jenis bahan baku yang digunakan(Hutomo 2012; Bouredja et al. 2015)

Pada beberapa penelitian belum diketahui secara pasti berapa konsentrasi $\mathrm{NaOH}$ dan lama waktu proses delignifikasi yang digunakan dalam proses ekstraksi selulosa batang tanaman jagung. Komponen selulosa pada batang tanaman jagung yang tinggi tersebut berpeluang sebagai salah satu alternatif sumber selulosa untuk berbagai kebutuhan industri.

\section{METODOLOGI}

\section{Bahan dan Alat}

Bahan utama yang digunakan adalah batang tanaman jagung yang diambil dari pertanian di Wonogiri. Bahan kimia dan penunjang antara lain : $\mathrm{NaOH}, \mathrm{NaOCl}$, aquadest, selulosa komersil murni dari SIGMA. Peralatan yang digunakan pada penelitian ini antara lain (1) peralatan dapur seperti : pisau, 
talenan, timbangan, baskom, sarangan, blender dan kompor, serta (2) peralatan laboratorium meliputi : timbangan analitik (Sartorius), oven (IK Oven Carbolite), eksikator, sentrifuse dan peralatan gelas yang mendukung antara lain gelas ukur, erlenmeyer, botol timbang, dan gelas beker

\section{Tahapan Penelitian}

Penelitian ini dirancang dalam beberapa tahap yaitu pertama ekstraksi selulosa dari batang tanaman jagung, tahap kedua karakterisasi sifat fisik dan kimia selulosa hasil esktraksi. Rancangan percobaan digunakan pada penelitian ini adalah rancangan acak lengkap (RAL) pola faktorial dengan dua faktor perlakuan, yaitu lama waktu $(T)$ dengan 3 taraf perlakuan, $T 1=60$ menit, $\mathrm{T} 2=90$ menit, $\mathrm{T} 3=120$ menit dan Konsentrasi $\mathrm{NaOH} \quad(\mathrm{K})$ dengan 5 taraf perlakuan, $\mathrm{K} 1=10 \%, \mathrm{~K} 2=15 \%, \mathrm{~K} 3=20 \%$, $\mathrm{K} 4=25 \%$ dan $\mathrm{K} 5=30 \%$. Masing-masing perlakuan diulang sebanyak dua kali. Sehingga diperoleh unit percobaan $3 \times 5 \times 2=$ 30 unit percobaan. Analisis laboratorium meliputi analisis fisik dan kimiawi pada selulosa yaitu: rendemen, kadar air, $\mathrm{pH}, \mathrm{WHC}$ (water holding capacity) dan $\mathrm{OHC}$ (oil holding capacity). Data yang diperoleh dari analisis fisik dan kimiawi dihitung secara statistik menggunakan software SPSS 17 dengan metode ANOVA kemudian dilanjutkan dengan uji Duncan's Multiple Range Test (DMRT) jika terdapat perbedaan yang nyata antar perlakuan.

\section{Ekstraksi Selulosa Batang Tanaman Jagung.}

Sampel batang tanaman jagung dipotong-potong kecil sampai dengan ukuran kurang lebih $5 \mathrm{~cm}$ kemudian dikeringkan. Setelah kering, potongan batang tanaman jagung dihancurkan dan diayak agar mendapatkan serbuk dengan ukuran yang seragam. Bubuk batang tanaman dimasak dengan larutan $\mathrm{NaOH}$ dengan variasi konsentrasi 10,15, 20, 25, dan 30\% untuk melarutkan bahan-bahan non selulosa pada suhu $100^{\circ} \mathrm{C}$ dengan variasi lama waktu 60,90 , dan 120 menit. Padatan yang tersisa yaitu ampas diambil kemudian dicuci dengan air bersih.

Ampas yang telah bersih kemudian dibleaching dengan menggunakan larutan $\mathrm{NaOCl}$. Pisahkan kembali ampasnya kemudian dicuci dengan air bersih hingga tidak berbau hipoklorit. Selulosa yang diperoleh dikeringkan dengan menggunaan oven pada suhu $60^{\circ} \mathrm{C}$ selama 24 jam sehingga diperoleh selulosa kering. Tahap selanjutnya lembaran selulosa kering dihancurkan dengan menggunakan mesin penggiling untuk memperoleh tepung selulosa kemudian dianalisis karakter fisik dan kimia.

\section{HASIL DAN PEMBAHASAN}

Batang tanaman jagung digunakan sebagai bahan utama ekstraksi selulosa. Tujuan dari penelitian ini adalah untuk mengetahui pengaruh konsentrasi $\mathrm{NaOH}$ dan lama waktu blanchingpadaproses delignifikasi selulosa batang tanaman jagung terhadap rendemen serta karakteristik fisik dan kimia.

\section{Rendemen Selulosa}

Hasil perhitungan rendemen selulosa dari proses ekstraksi batang tanaman jagung menggunakan $\mathrm{NaOH}$ dengan variasi konsentrasi $10 \%, 15 \%, 20 \%$, $25 \%$ dan $30 \%$ dan 3 variasi lama waktu pemasakan yaitu 60 menit, 90 menit dan 120 menit menghasilkan rendemen berkisar antara 30,65 - 36,25\%, dengan rendemen rata-rata sebesar $33,54 \%$. Nilai rendemen berturut-turut sebesar $32,41 \%, 33,19 \%, 34,80 \%, 35,61 \%$ dan $31,67 \%$. Data lengkap dapat dilihat pada Tabel 1. Dari data lama waktu pemasakan 60 menit dan 90 menit terlihat bahwa rendemen selulosa dari proses delignifikasi metode basa, pada konsentrasi $\mathrm{NaOH} 10 \%$ sampai dengan konsentrasi $\quad \mathrm{NaOH} \quad 25 \% \quad$ mengalami peningkatan karena $\mathrm{NaOH}$ memiliki kemampuan melepas ikatan selulosa dari lignin, pektin dan hemiselulosa pada batang jagung. Sementara itu, pada konsentrasi $\mathrm{NaOH} 30 \%$ rendemen selulosa mengalami penurunan.

Penurunan rendemen selulosa pada konsentrasi $\mathrm{NaOH} \quad 30 \%$ tersebut diduga karena komponen hemiselulosa dan lignin pada batang tanaman jagung telah terhidrolisis menjadi glukosa yang larut dalam proses pencucian dengan menggunakan air. Pecahnya komponen hemiselulosa dan lignin menjadi senyawa yang lebih sederhana seperti glukosa yang larut dalam air dapat berpengaruh terhadap produksi selulosa yang dihasilkan. Hasil penelitian ini sesuai dengan hasil penelitian yang dilakukan oleh (Widodo et al. 2013; Hutomo 2012; Lisin et al. 2015) yang menyatakan bahwa konsentrasi $\mathrm{NaOH}$ dan lama waktu blancing berpengaruh pada hasil rendemen selulosa yang dihasilkan. Penggunaan $\mathrm{NaOH}$ dengan konsentrasi yang lebih tinggi akan menyebabkan degradasi 
Versi Online:

http://www.profood.unram.ac.id/index.php/profood e-ISSN: 2443-3446

terhadap selulosa, sehingga menyebabkan turunnya kadar selulosa yang diperoleh pada hasil ekstraksi. Secara umum, hasil pengujian statistik menunjukan tidak berbeda nyata pada nilai rendemen selulosa sehingga dapat diartikan bahwa penggunaan konsentrasi $\mathrm{NaOH} 10 \%$ dan blanching selama 60 menit sudah dapat diperoleh selulosa dari batang tanaman jagung.

Tabel 1. Rendemen Ekstraksi Selulosa Batang Jagung

\begin{tabular}{cccc}
\hline \multicolumn{3}{c}{ Rendemen (\%) } \\
\hline \%NaOH & 60 Menit & 90 Menit & 120 Menit \\
$\mathbf{1 0}$ & 32.41 & 32.34 & 30.65 \\
$\mathbf{1 5}$ & 33.19 & 33.19 & 32.53 \\
$\mathbf{2 0}$ & 34.80 & 34.20 & 34.85 \\
$\mathbf{2 5}$ & 35.61 & 33.48 & 34.60 \\
$\mathbf{3 0}$ & 31.67 & 30.95 & 36.25 \\
\hline
\end{tabular}

Tabel 2. Kadar Air Selulosa Batang Jagung

\begin{tabular}{cccc}
\hline \multicolumn{4}{c}{ Kadar Air (\%) } \\
\hline $\mathbf{\% N a O H}$ & 60 Menit & 90 Menit & 120 Menit \\
$\mathbf{1 0}$ & $7.96 \mathrm{a}$ & $11.04 \mathrm{a}$ & $10.67 \mathrm{a}$ \\
$\mathbf{2 0}$ & $8.48 \mathrm{ab}$ & $11.36 \mathrm{ab}$ & $12.77 \mathrm{ab}$ \\
$\mathbf{2 5}$ & $8.02 \mathrm{ab}$ & $11.59 \mathrm{ab}$ & $13.64 \mathrm{ab}$ \\
$\mathbf{3 0}$ & $8.53 \mathrm{ab}$ & $11.16 \mathrm{ab}$ & $12.73 \mathrm{ab}$ \\
\hline
\end{tabular}

Subscrip yang berbeda menunjukan berbeda nyata

\section{Kadar Air}

Hasil kadar air selulosa batang tanaman jagung hasil ekstraksi dapat dilihat pada Tabel 2. Rata-rata kadar air selulosa dari semua perlakuan yaitu $7,96 \%$, nilai kadar air tertinggi berbeda nyata pada proses blancing menggunakan $\mathrm{NaOH}$ konsentrasi $30 \%$ sebesar $10,02 \%$. Peningkatan konsentrasi $\mathrm{NaOH}$ pada proses dilignifikasi selulosa dapat mendorong peningkatan kadar air rendemen selulosa yang dihasilkan. Hal tersebut disebabkan karena terjadinya peningkatan molekul air selama proses tersebut berlangsung sebagai akibat dari proses reaksi alkalisasi oleh $\mathrm{NaOH}$ terhadap selulosa yang menghasilkan kompleks selulosa-alkali dan air $\left(\mathrm{H}_{2} \mathrm{O}\right)$ (Muzaifa 2006).

\section{Sifat pH Selulosa Batang Jagung}

Nilai $\mathrm{pH}$ hasil pengukuran pada selulosa ekstraksi batang tanaman jagung menggunakan rata-rata 8,66. Nilai $\mathrm{pH}$ dipengaruhi oleh larutan basa $\mathrm{NaOH}$ yang digunakan untuk melakukan blancing pada proses ekstraksi selulosa batang tanaman jagung. Nilai $\mathrm{pH}$ masing-masing pada konsentrasi $\mathrm{NaOH} 10,15,20,25$ dan 30\% berturut-turut 8,$33 ; 8,58 ; 8,69 ; 8,87$ dan 8,84 , berdasarkan uji statistik tidak terdapat perbedaan nyata pada seluruh sampel. Proses perendaman menggunakan $\mathrm{NaOCl}$ dan proses pencucian menggunakan aquadest setelah proses alkalisasi menggunakan $\mathrm{NaOH}$ diduga sebagai penyebab kecendrungan nilai $\mathrm{pH}$ yang sama pada selulosa hasil ekstraksi. yang dilakukan menggunakan Nilai pH dapat dilihat pada grafik Gambar 1.

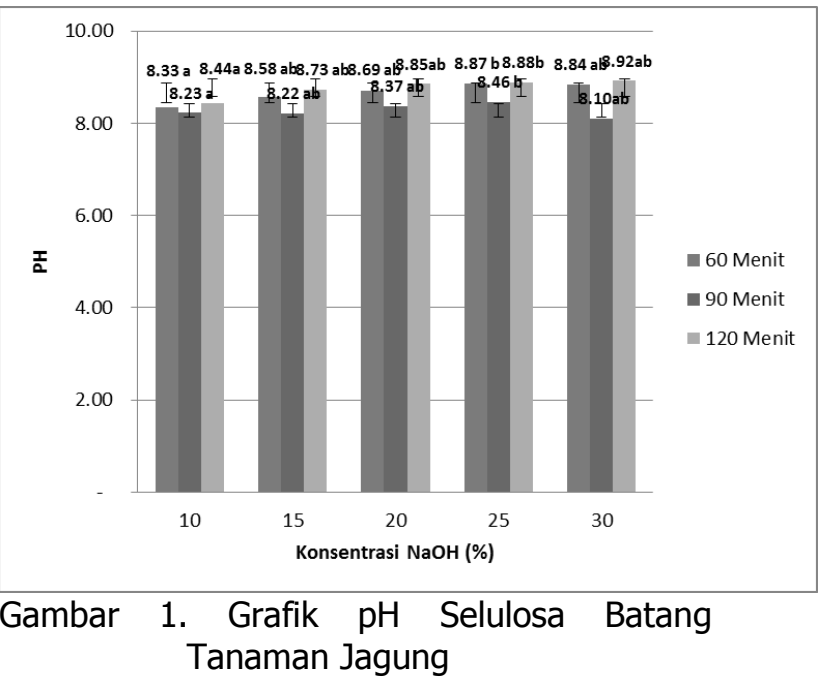

\section{Water Holding Capacity (WHC) dan Oil Holding Capacity (OHC)}

Hasil nilai WHC (kemampuan selulosa mengikat air) pada pengujian selulosa batang jagung sebesar $7,87 \mathrm{~g} / \mathrm{g}$. Nilai tertinggi sebesar 8,21 $\mathrm{g} / \mathrm{g}$ pada penggunaan konsentrasi $\mathrm{NaOH} 25 \%$. Secara umum, dari hasil uji statistik selulosa batang jagung ekstraksi variasi konsentrasi $\mathrm{NaOH} 10-30 \%$ memiliki nilai WHC tidak berbeda nyata (Gambar 2).

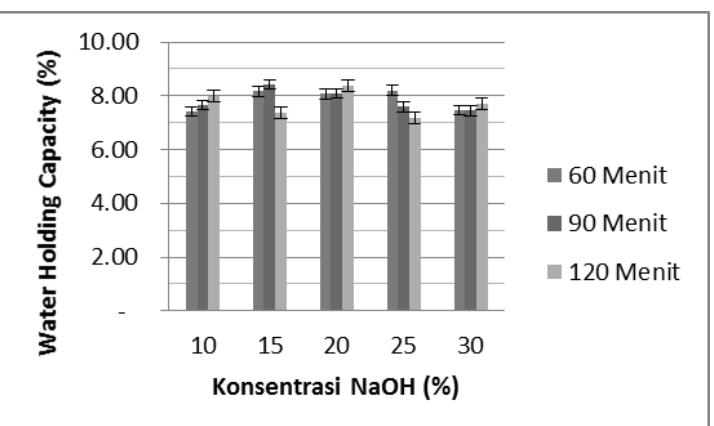

Gambar 2. Kemampuan Selulosa Mengikat Air (WHC) 
Kemampuan selulosa dalam mengikat minyak yang dinyatakan sebagai oil holding capacity $(\mathrm{OHC})(\mathrm{g} / \mathrm{g})$ menggunakan $\mathrm{NaOH}$ rata-rata sebesar 9,16 g/g. Kemampuan mengikat minyak yang paling tinggi pada selulosa hasil ekstraksi menggunakan $\mathrm{NaOH}$ konsentrasi $30 \%$ selama 90 menit, dibandingkan dengan penggunaan konsentrasi $\mathrm{NaOH}$ lebih rendah atau lebih tinggi (Gambar 3).

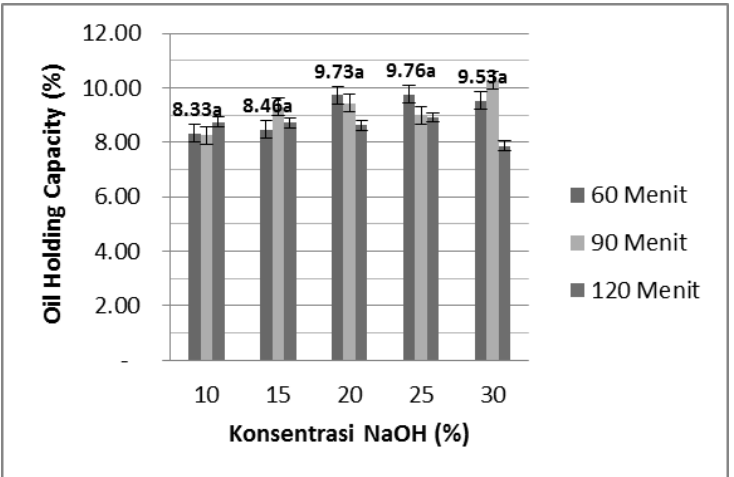

Gambar 3. Kemampuan Selulosa Mengikat Minyak (OHC)

\section{DAFTAR PUSTAKA}

Azubuike CP dan Okhamafe AO. 2012. Physicochemical, spectroscopic and thermal properties of microcrystalline cellulose derived from corn cobs. International Journal of Recycling of Organic Waste in Agriculture, 1(1): 9.

Bono A. 2009. Synthesis and Characterization of Carboxymethyl Cellulose from Palm Kernel Cake. Advances in Natural and Applied Sciences, 3(1): 5-11.

Bouredja N, Mehdadi Z dan Bouredja M. 2015. Extraction of the cellulose and the biometrics of the fibers of the pods of Retamamonosperma ( $L$.). Boissgrowingin natural conditions in the Algerian Western Coast. International Journal of Biosciences, 6(10): 31-38.

Espinoza-Herrera N. 2011. Thermal, Mechanical and Microstructures Properties of Cellulose Derivatives Films: A Comparative Study. Food Biophysics, 6(1):106-114.

Hutomo. 2012. Cellulose Extraction from Cacao Pod Husk Using Sodium Hydroxide , 32(3): 223-229.

Israel AU, Obot IB dan Umoren SA. 2008. Production of Cellulosic Polymers from
Proses hidrolisis oleh $\mathrm{NaOH}$ pada selulosa menyebabkan perubahan struktur selulosa sehingga mendorong air dan minyak akan semakin mudah menembus struktur selulosa yang melonggar akibat proses tersebut. Sejalan dengan penelitian Hutomo (2012) ekstraksi selulosa dari Pod Husk kakao menggunakan $\mathrm{NaOH}$ dengan konsentrasi 4$16 \%$ tertinggi sebesar $3,24 \mathrm{~g} / \mathrm{g}$.

\section{KESIMPULAN}

Penggunaan $\mathrm{NaOH}$ konsentrasi $10 \%$ dan lama waktu 60 menit pada proses ekstraksi selulosa batang jagung dapat menghasilkan rendemen sebesar 32,41\%; nilai $\mathrm{pH} 8,33$; WHC rata-rata 7,8 ; $\mathrm{OHC}$ ratarata 8,33 dan kadar air rata-rata $7,96 \%$. Ekstraksi selulosa metode basa menggunakan larutan $\mathrm{NaOH}$ dapat digunakan untuk mendorong proses pemecahan komponen lignoselulosa sehingga menghasilkan komponen selulosa tidak larut air pada proses blancing dan pencucian.

Agricultural Wastes. E-Journal of Chemistry, 5(1): 81-85.

Jahit IS. 2016. Preparation and Physical Properties of Gelatin/CMC/Chitosan Composite Films as Affected by Drying Temperature. International Food Research Journal, 23(3): 1068-1074. Available at: http://www.ifrj.upm.edu.my.

Lisin N. 2015. Hydrolysis of Cellulose from Cocoa Pod Husk Using Sulfuric Acid. 3(4): 482-490.

Malmiri HJ. 2011. Evaluation of effectiveness of three cellulose derivative-based edible coatings on changes of physico-chemical characteristics of "Berangan" banana (Musa sapientum cv. Berangan) during storage at ambient conditions. International Food Research Journal, 18(4):1381-1386.

Melisa, Bahri S dan Nurhaeni. 2014. Optimization Synthesis Corboxymethyl Cellulose Of Sweet Corn Cob (Zea Mays $\angle$ Saccharata). Online Jurnal of Natural Science, 3(2): 70-78.

Muzaifa M. 2006. Pembuatan CMC Dari Selulosa Bakterial (Nata De Coco). Agrista, 10(2):100-106

Sarkar N. 2012. Bioethanol production from 
Versi Online:

http://www.profood.unram.ac.id/index.php/profood e-ISSN: 2443-3446

agricultural wastes: An overview. Renewable Energy, 37(1): 19-27. Available at

http://dx.doi.org/10.1016/j.renene.2011. 06.045.

Veeramachineni AK, Sathasivam $T$ dan Muniyandy S. 2016. Optimizing Extraction of Cellulose and Synthesizing Pharmaceutical Grade Carboxymethyl Sago Cellulose from Malaysian Sago Pulp. Applied Sciences, 6(170).

Widodo LU. 2013. Pemisahan Alpha-Selulosa Dari Limbah batang Ubi kayu
Pro Food (Jurnal IImu dan Teknologi Pangan) Vol 4 No. 1 Mei 2018 ISSN: 2443-1095

Menggunakan Larutan Natrium Hidroksida. Jurnal Teknik Kimia, 7(2): 43-47.

Wijayani A, Ummah K \& Tjahjani S. 2005. Karakterisasi Karboksimetil Selulosa (CMC) dari Eceng Gondok (Eichornia crassipes (Mart) Solms). Indo J Chem, 5(3): 228-231.

Yan FYAN. 2009. Cellulose Extraction From Palm Kernel Cake Using Liquid Phase Oxidation. J of Engineering Science and Technology,

57-68. 